\title{
Functional analysis of $B$ and $C$ class floral organ genes in spinach demonstrates their role in sexual dimorphism
}

\author{
D Noah Sather1,2, Maja Jovanovic'1 and Edward M Golenberg*1
}

\begin{abstract}
Background: Evolution of unisexual flowers entails one of the most extreme changes in plant development. Cultivated spinach, Spinacia oleracea L., is uniquely suited for the study of unisexual flower development as it is dioecious and it achieves unisexually by the absence of organ development, rather than by organ abortion or suppression. Male staminate flowers lack fourth whorl primordia and female pistillate flowers lack third whorl primordia. Based on theoretical considerations, early inflorescence or floral organ identity genes would likely be directly involved in sex-determination in those species in which organ initiation rather than organ maturation is regulated. In this study, we tested the hypothesis that sexual dimorphism occurs through the regulation of B class floral organ gene expression by experimentally knocking down gene expression by viral induced gene silencing.

Results: Suppression of B class genes in spinach resulted in the expected homeotic transformation of stamens into carpels but also affected the number of perianth parts and the presence of fourth whorl. Phenotypically normal female flowers developed on SpPI-silenced male plants. Suppression of the spinach C class floral organ identity gene, SpAG, resulted in loss of reproductive organ identity, and indeterminate flowers, but did not result in additional sex-specific characteristics or structures. Analysis of the genomic sequences of both SpAP3 and SpPI did not reveal any allelic differences between males and females.

Conclusion: Sexual dimorphism in spinach is not the result of homeotic transformation of established organs, but rather is the result of differential initiation and development of the third and fourth whorl primordia. SpAG is inferred to have organ identity and meristem termination functions similar to other angiosperm C class genes. In contrast, while SpPI and SPAP3 resemble other angiosperms in their essential functions in establishing stamen identity, they also appear to have an additional function in regulating organ number and identity outside of the third whorl. We present a model for the evolution of dioecy in spinach based on the regulation of B class expression.
\end{abstract}

\section{Background}

The ABC model for floral development has been extensively tested and applied to a wide variety of angiosperm species and has been found to be broadly conserved on sequence, expression, and functional levels. Nonetheless, those few exceptions to the canonical Arabidopsis/Antirrhinum model have been illuminating in understanding the processes involved in the evolution of the present array of floral morphologies [1]. For example, expanded B class expression appears to be common in the Liliaceae and can

* Correspondence: egolenb@biology.biosci.wayne.edu

1 Department of Biological Sciences, Wayne State University, Detroit, Ml 48202, USA

Full list of author information is available at the end of the article explain the morphological similarities of first and second whorl organs [2-5]. A number of species in the basal dicots display an analogously modified B class expression domain consistent with a gradient in sterile and reproductive organ morphology [6]. Similarly, novel temporal and spatial expression domains have been associated with novel organ morphologies [7-9]. In contrast, the assumption of the general conservation of expression has been used to assign homology of highly derived organs to putative ancestral forms [10-14]. Lastly, evolution of the coding sequences and their regulation following gene duplications have lead to lineage specific partitioning of function or development of new gene functions $[15,16]$. 
Among the most extreme examples of evolution of the reproductive organs in flowers is the development of unisexual flowers. Unisexuality has evolved independently in all orders of angiosperms. Morphologically, there appears to be two ways in which unisexual flowers arise, one in which initiated organs are aborted during development, and one in which stamens and/or carpels are never initiated [17]. Golenberg and Freeman [18] argued that floral organ identity genes, particularly B and C class genes, will not be instrumental in the sex-determination regulatory process in those species that achieve unisexuality by organ abortion. In those species, altered temporal or spatial expression of these genes will likely be a secondary outcome of the degeneration of the organs. Several well studied species develop this way, including Zea mays [19], Rumex acetosa [20], Cucumis sativus [21], and Silene latifolia [22-24]. In comparison, $\mathrm{B}$ and $\mathrm{C}$ class genes are more likely to be directly involved in sex-determination in those species in which organ initiation is regulated. Studies in Thalictrum dioicum [25] and Spinacia oleracea [26,27] demonstrate that some of the B and C class paralogues are alternatively expressed in either male or female flowers.

Diploid cultivated spinach, Spinacia oleracea, develops by differential organ initiation $[27,28]$. Female, or pistillate flowers develop two sepaloid perianth organs in the first whorl, no organs in what would be the second and third whorls, and a single ovule and ovary in the fourth whorl. In contrast, male, or staminate flowers develop two sequential pairs of sepaloid organs in the first whorl, no petals in the second whorl, four stamens in the third whorl, and no organs in the fourth whorl. We have shown that both B and $\mathrm{C}$ class genes are either alternatively expressed or spatially regulated in a sex-specific manner. The spinach $\mathrm{C}$ class gene $\operatorname{SpAGAMOUS}$ ( $\operatorname{SpAG}$ ) is expressed early throughout the floral primordium before the emergence of floral organ primordia in both males and female [27]. Later in development, $\operatorname{Sp} A G$ expression is sex-specific and becomes restricted to the microsporangial cells in males and the nucellus in females. In contrast, the spinach B class genes SpPISTILLATA (SpPI) and SpAPETALA3 (SpAP3) were found to have highly sex-specific expression patterns [26]. SpAP3 was found by RT-PCR and northern blot to be strongly expressed in male flowers and weakly expressed in female flowers, although expression was undetectable in female flowers by in-situ hybridization. SpPI was found to be expressed early in male floral development and not in female floral development at any stage. Given that spinach $\mathrm{B}$ class genes are expressed before the initiation of floral organ primordia in a sex-specific manner, we hypothesized that one or both are directly involved in sex determination in this species, with SpPI being the most likely agent. In contrast, early $\mathrm{C}$ class expression in both males and females would suggest that the later sex-specific spatial expression patterns are likely a consequence of a sex-specific regula- tory program and are involved in the sexual dimorphism rather than in the sex determination, itself.

To test this hypothesis, we analyzed the function of the spinach B (SpPI and SpAP3) and C $(S p A G)$ class genes by suppressing individual gene expression during floral development. We demonstrate that both B and $\mathrm{C}$ class genes retain organ identity function as first described in Arabidopsis. SpAG also functions both in microsporangial development in males and in meristem determination in females. The spinach B class genes SpPI and SpAP3 are also required for normal organ number, whorl development, and sex determination. The lack of detected allelic differences in B class genes in males versus females implies that gender-specific development is controlled through trans-acting regulators of $\mathrm{B}$ class expression. These results indicate that regulation of $\mathrm{B}$ class genes is a major control point in sexdetermination in spinach.

\section{Results}

Infection with pWSRi:SpAP3 causes homeotic transformations in males and hermaphroditic flowers

Spinach plants were treated with the gene silencing plasmid pWSRi:SpAP3 by biolistic bombardment with coated tungsten particles. Approximately five to six weeks post inoculation, all plants had transitioned to flowering. Approximately half of the original plants had differentiated into female plants. Wild-type female plants develop flowers with two sepaloid organs and a single central carpel (Figure 1b). The $p W S R i: S p A P 3$ female plants were normal in appearance, with flowers developing two sepals and a single carpel. The female flowers were fertile, producing seeds after pollination. The remaining half of the treated plants differentiated into male. Wild-type male flowers develop four stamens and four sepaloid organs, with no central carpel (Figure 1a). All pWSRi:SpAP3 treated males had phenotypic defects in development in some flowers. Several flowers had homeotic transformations of stamens into carpels, producing flowers with mixed organs in the third whorl (Figure 1c and 1d). These mixed organ flowers did not develop a fourth whorl, but developed carpels in the third whorl in the place of stamens. Some carpels developed with more than the usual four stigmatic arms such as shown in Figure 1c. The stamens in the mixed organ flowers sometimes did not fully mature and produce pollen. A number of plants developed flowers that appeared to be fully hermaphroditic (Figure 1e) with four sepals, four stamens, and a single fourth whorl ovary. Some flowers had the normal complement of four sepals, but developed a single central carpel and no stamens (Figure 1f).

\section{Infection with pWSRi:SpPI causes homeotic transformations and floral gender transformation}

Approximately five to six weeks post inoculation with $p W S R i: S p P I$, all plants had transitioned to flowering, with 


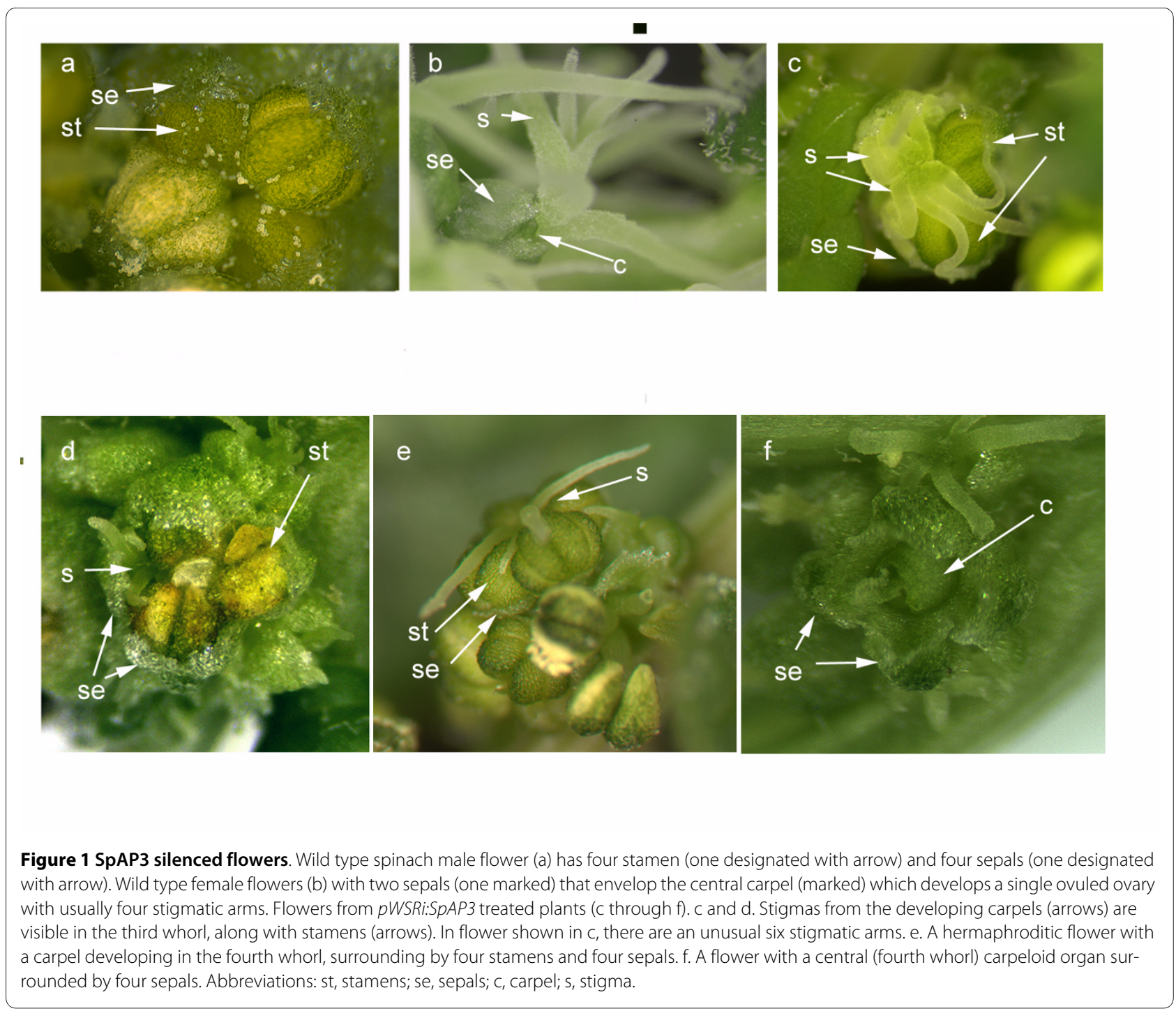

approximately half developing as male and half developing as female plants. The female $p W S R i: S p P I$ plants all developed normal female flowers, and produced seed following pollination. All $p W S R i: S p P I$ treated plants that developed into male plants produced flowers with phenotypic defects. Several flowers had active growth in the fourth whorl, some with full carpel development (Figure 2a). Other flowers exhibited homeotic transformations of stamens into carpels in the third floral whorl. As seen with $p W S R i: S p A P 3$ male plants, the stamens in the mixed organ flowers sometimes arrested development and did not produce pollen. Several flowers had complete homeotic transformations of stamens to carpels, developing a ring of four carpels with four outer whorl sepals (Figure 2b).

The earliest flowers in $p W S R i: S p P I$ males developed mostly male floral organs, whereas flowers produced later tended to show progressively more severe transformations of organ identity. Inflorescences in the upper portion of the plant had a range of flowers, including male flowers, mixed organ flowers, and female flowers. Most flowers at the shoot apex developed as normal females, indicating a complete transformation of floral identity from male to female (Figure 2c). These results indicate that $S p P I$ and $S p A P 3$ have prominent roles in the regulation of sexual dimorphism beyond homeotic transformation of single organs.

\section{qRT-PCR and in situ characterization of pWSRi:SpPI infected plants demonstrate that SpPI mRNA levels are} specifically decreased

To determine whether the phenotypic results obtained in $p W S R i$ treated plants were associated with gene specific knockdown, we quantified the relative amounts of $S p P I$ mRNA in inflorescences of male plants treated either with $p W S R i$ or $p W S R i: S p P I$. cDNA was prepared from total RNA extracted from inflorescences. Spinach G6pdh mRNA was targeted as the control gene to be compared with SpPI mRNA levels. The ct values are given in Table 1 . The delta- 


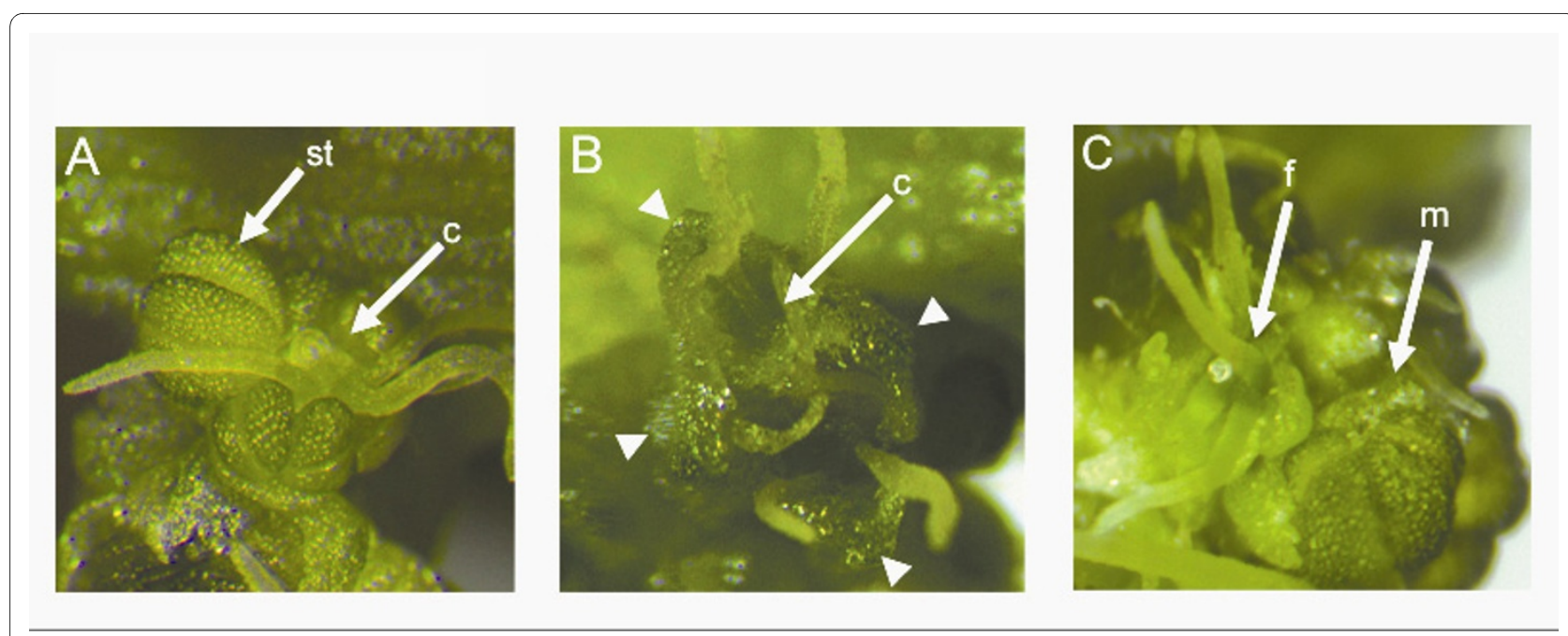

Figure 2 SpPI-silenced flowers. a. Mixed flower with stamen (st) and fourth whorl carpel (c). b. Flower with four sepals (indicated by arrowheads) and four carpels in the third whorl. c. Adjacent male $(m)$ and female $(f)$ flowers.

delta ct value was 1.113, which is significant at the $\mathrm{p}<$ 0.001 level. This corresponds to a reduction in relative $S P P I$ mRNA in the $p W S R i: S p P I$ treated plant of approximately $55 \%$ compared to the control. This level of knockdown is in the lower range for $p W S R i$ gene silencing reported elsewhere [29], but is consistent with the mixture of phenotypically wild type and mutant flowers found in the inflorescence. These results indicate, therefore, that the level of $S p P I$ mRNA was specifically reduced in plants treated with $p W S R i: S p P I$.

To assess how infection with $p W S R i: S p P I$ affected spatial expression in relation to morphological variation, infected plants were prepared for in situ hybridization. After plants were scored for phenotypes, $p$ WSRi:SpPI male inflorescences were fixed, imbedded and thin sectioned. The sections were hybridized with digoxigenin labeled antisense RNA probes of $S p P I, S p A P 3$, and $S p A G$. In sections of flowers with mixed organs, $S p P I$ was expressed in the stamens, but not in the carpels. Figure 3a shows a longitudinal section through a flower with a stamen and an ovary both in the third whorl. The stamen has pollen grains in the locules. The tapetal cells surrounding the locules are strongly stained, indicating $S p P I$ expression. In contrast, there is no $S p P I$ hybridization detected in the ovary opposite the stamen. Although occurring in differentiated organs in a single whorl, the SPPI expression patterns are similar to those reported in the comparable organs in wild type plants [27]. Figure $3 \mathrm{~b}$ shows an early stage 5 female flower (marked f) and a late stage 3 male flower (marked $\mathrm{m}$ ) in the same inflorescence cluster. As in wild type, there is no detectable expression of $S p P I$ in the female flower. In contrast, there is $S p P I$ hybridization in clusters of L2 cells in the region of the incipient stamen primordium. Hybridization of $S p P I$ sense RNA probes to $p W S R i: S p P I$ sections gave no signal (Figure 3e). These results demonstrate that suppression of $\mathrm{SpPI}$ expression correlates with homeotic organ transformation within a single flower, and perhaps induction of complete female flower development on a male plant.

In Arabidopsis AP3 and PI work as an obligate heterodimer that is required for maintenance of both genes' expression [30]. If one B class gene is not expressed, then the other gene will not be expressed after its initial induction. To test how silencing of $S p P I$ affected $S p A P 3$ expression, $p W S R i: S p P I$ male flowers with mixed organs were hybridized with a probe for $S p A P 3$. Figure 3c shows a cross section through a flower with three stamens and a carpel in the third whorl. As with $S p P I, S p A P 3$ was only expressed in the tapetal cells surrounding the vacuoles in the near-mature anthers. Although also in the third whorl, the ovary does not display any $S p A P 3$ expression. Given that this tissue was silenced only for SpPI, the expression patterns indicate that

Table 1: qRT-PCR analysis of $p W S R i: S p P I$ treated plants.

\begin{tabular}{lccc}
\hline Treatment & Mean ct G6pdh & Mean ct SpPI & ct \\
\hline$p W S R i$ & $20.565 \pm 0.166$ & $17.465 \pm 0.105$ & -3.100 \\
$p W S R i: S p P I$ & $21.192 \pm 0.307$ & $19.205 \pm 0.118$ & -1.988 \\
\hline
\end{tabular}

Mean threshold cycle number \pm standard deviations and difference values are listed. ${ }^{* * *}$ significant at $\mathrm{p}<0.001$ 


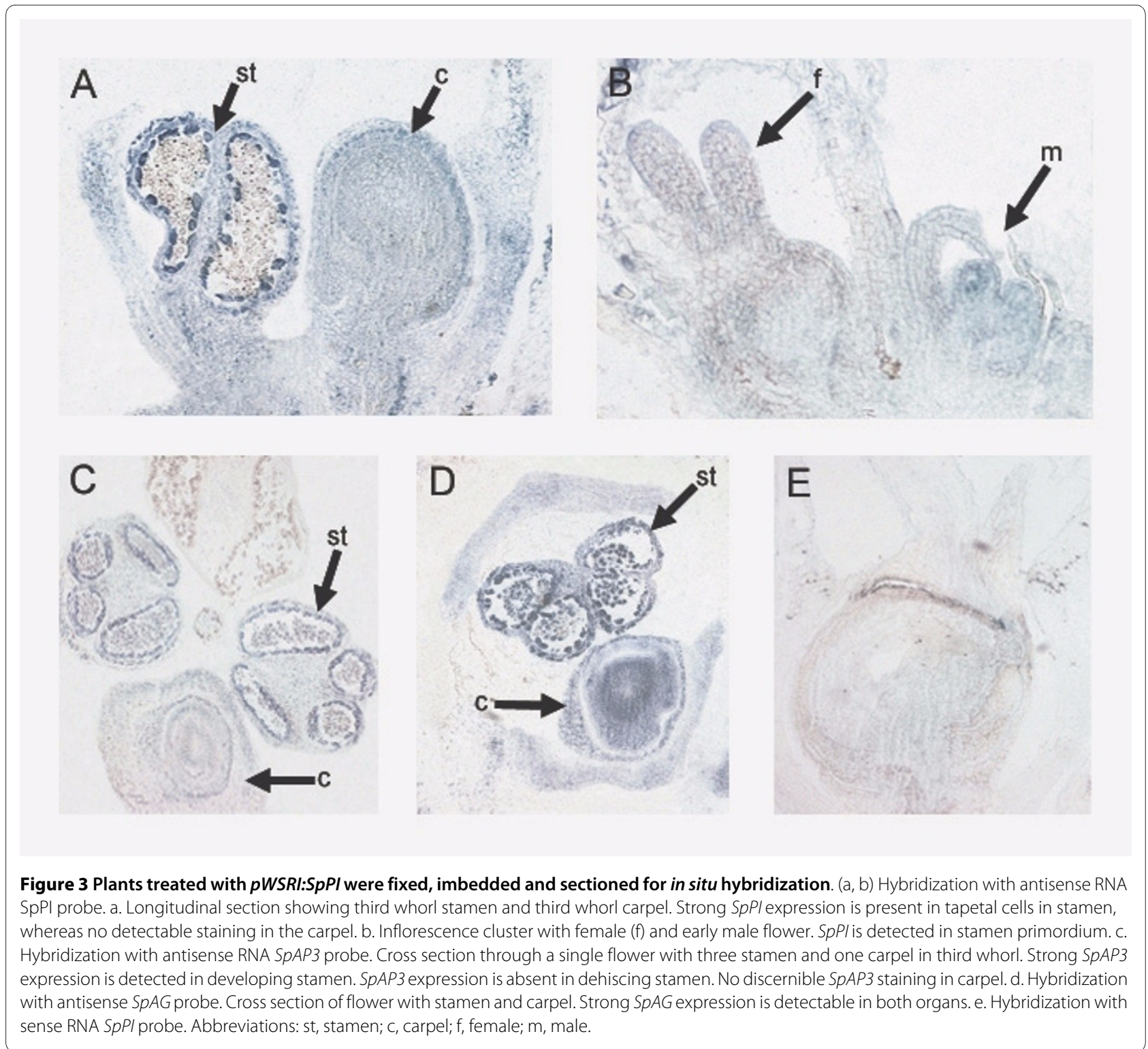

$\mathrm{SpPI}$ is necessary for $\mathrm{SpAP} 3$ expression as was previously found in Arabidopsis.

Both to test for any regulatory interactions between $S p P I$ and $S p A G$ and to serve as a positive control, $p W S R i: S p P I$ mixed flowers were hybridized with antisense RNA probes for $S p A G$. As previously reported in wild type flowers [27], $S p A G$ is expressed in both anthers and in the ovary. Figure $3 \mathrm{~d}$ is a cross-section through a flower with an ovary opposite at stamen. $\operatorname{SpAG}$ is detected in the developing ovule as well as in the stamen. There is strong expression in a ring of cells surrounding the center of the ovule that likely corresponds to the nucellus. There is weak or background expression in the surrounding integuments and ovary wall. Thus, expression of $\operatorname{SpAG}$ was unaltered from what we have previously reported. This shows that $S P P I$ is not required for regulation of the $\mathrm{C}$ class gene in spinach. In concert, the quantitative RT-PCR and in situ hybridization results indicate that the phenotypic effects found in $p W S R i: S p P I$ treated plants is directly associated with a gene specific knockdown of $S p P I$ mRNA.

\section{There is no evidence of gender-specific allelic states in SpPI or SpAP3}

Previous studies of B class expression [26] and the present results indicate that regulation of B class genes functionally differentiates male and female flower development in spinach. The results do not, however, distinguish between gender-specific trans- or cis regulatory effects, the latter of which could be detected as allelic differences in the $S p P I$ and/or $S p A P 3$ loci in male versus female individuals. To test for allelic variation, especially in LEAFY binding regions, we isolated genomic DNA from three male and 
three female individuals for both $S p P I$ and $S p A P 3$ DNA analysis. A combination of regular and splinkerette [31] PCR was performed to obtain full genomic sequences. After obtaining the complete sequence from a single individual, primers were designed such that sequential regions were amplified so as to overlap with adjacent regions. As a result, all sections of the genes were isolated in at least two independent PCR reactions for each individual surveyed. Sequences were determined from amplified products rather than clones to avoid sampling error or cloning induced artifacts.

The intron-exon structure of the spinach B class genes was predicted based on a comparison with previously published cDNA sequences. We obtained $6676 \mathrm{bp}$ of sequences for $S p A P 3$ starting 1737 bp upstream (5') of the start codon through to $182 \mathrm{bp}$ downstream (3') of the stop codon (Figure 4). The gene appears to contain seven exons and six introns. The sequence has been submitted to GenBank under accession number GQ120477.

Using a similar approach, we isolated $4309 \mathrm{bp}$ of the $S p$ PI gene through to the end of the stop codon (Figure 4). We sequenced 396 bp upstream of the start codon. As in $S p A P 3, S p P I$ has six introns and seven exons. The sequence has been submitted to GenBank under accession number GQ120478.

In both $S p A P 3$ and $S p P I$, we did not detect any sequence variation among the six individuals sequenced, including all coding and non-coding regions. To determine if there was any variation that was obscured in a heterozygous state in the direct sequencing, we cloned the $5^{\prime}$ non-coding region of $S p A P 3$, and sequenced eight individual clones each from one male and one female individual. We anticipated that if the differential regulation of transcription between the sexes were driven by allelic differences, they would be apparent in promoter regions. As with the direct sequencing, all sequences were identical. As the plants used are from a cultivated variety, we anticipated that there may be low sequence variation, however, the complete absence of detected variability even in the large introns and $5^{\prime}$ untranslated regions was unanticipated, and reflects the inbred nature of the cultivated variety.

We further scrutinized our sequences to determine whether potential cis regulatory sites could be found (Figure 4). Both LEAFY and MADS box proteins (AP1 and AP3/PI dimers) regulate $A P 3$ and $P I$ in Arabidopsis. Three CArG binding sites have been identified in the 5 ' region in Arabidopsis AP3 [32,33]. In the spinach AP3 sequences, there are two potential CArG boxes at sequence positions (relative to the start codon) -708 (GCAAATTAGG) and 384 (CCAAATTGC). A third potential CArG box (TCATATTTGG) is located in the second intron at position 785. Similarly. LEAFY binding sites have been determined in intronic regions in Arabidopsis B class genes [34,35]. The spinach SpAP3 sequences have one potential LEAFY bind- ing site in the second intron, (CCAATGT) at position 1372, and one in the fourth intron (CCATTGT) at position 3465. In comparison, SpPI has three potential CArG boxes: (CCATTATTGA) position -30 in the 5'UTR, (ACAAAAAAGG) position 1083 in the second intron, and (TCAAAAAAGG) position 3052 in intron 5. We detected a single potential LEAFY binding site (CCATTGT) in the second intron at position 1521. Thus, the sequence data indicate the existence of conserved potential cis regulatory elements in both male and female genes.

\section{SpAG specifies organ identity in the third and fourth whorls, specifies determinacy, and promotes stamen fertility}

The spinach $\mathrm{C}$ class homologue, $\operatorname{SpAG}$, is initially expressed throughout the early floral meristem in both males and females. However, as organ primordia begin to develop, $S p A G$ takes on a sex-specific expression pattern. Given that $S p A G$ is expressed in both developing stamens and carpels and given the apparent lack of regulation by $\mathrm{B}$ class genes demonstrated in $p W S R i: S p P I$ plants, we wished to determine the functional role of $\operatorname{SpAG}$ in developing flowers. Spinach plants were treated with $p W S R i: S p A G$ coated tungsten particles. Approximately six weeks after infection, plants began to develop phenotypically abnormal flowers. In females, extreme floral abnormalities developed in which floral organs were transformed into bract or leaflike organs bearing trichomes (Figure 5a). The organs tended to be arranged in a spiral phyllotaxy rather than in distinct whorls. The total number of floral organs increased to well above the normal three found in females, indicating a loss of determinacy in the flower. Several flowers produced continuous whorls of sepals, and then developed an entirely new inflorescence meristem from within the last whorl. Male flowers also often developed a new inflorescence meristem from the center of a flower (Figure 5b). These inflorescences were correctly structured and later produced flowers with $S p A G$-silenced phenotypes. Male $S p A G$-silenced plants also produced flowers that contained modified third whorl organs. The male flower in Figure $5 \mathrm{~b}$ next to the inflorescence has flat, sterile green organs instead of stamens. Other male flowers developed stamens, however these appeared to have stunted development and never produced pollen (Figure 5c). Therefore, the spinach $\mathrm{C}$ class gene has organ identity, microsporangial development, and floral determinacy functions similar to those reported in Arabidopsis. However, as anticipated from the Arabidopsis model, there were no instances in which flowers switched sex, indicating that regulation of the $\mathrm{C}$ class gene is not involved in the sex-determination pathway in this species. 
SpAP3
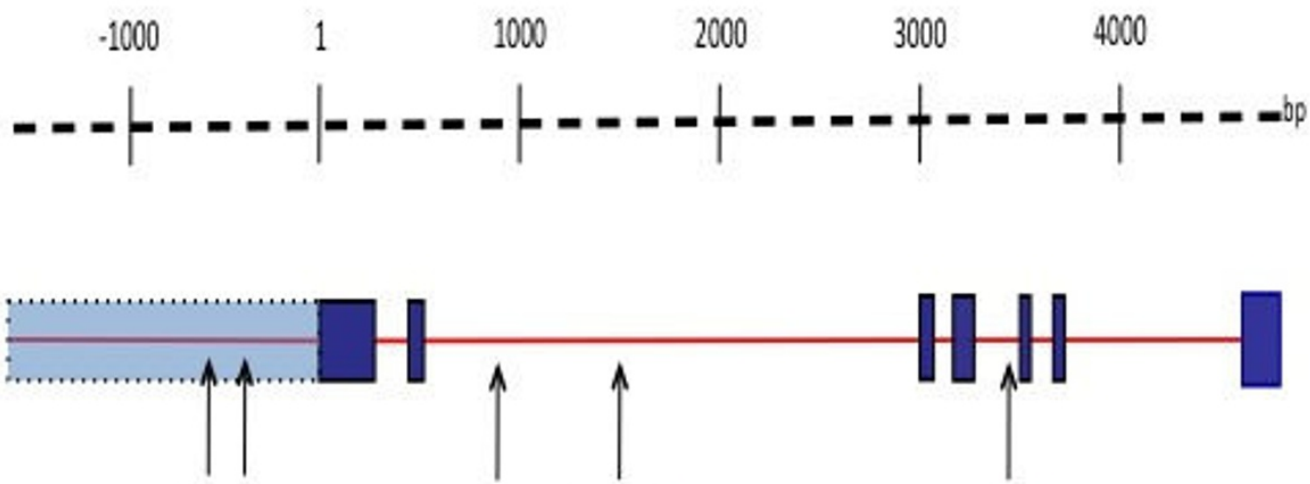

GCAAATTAGG

CCAAATTAGC

Potential CArG bowes

TCATATTIGG CCATGT

Potential LFY binding site

Potential CarG bou
CCATTGT

Potential LFY binding site

SpPI

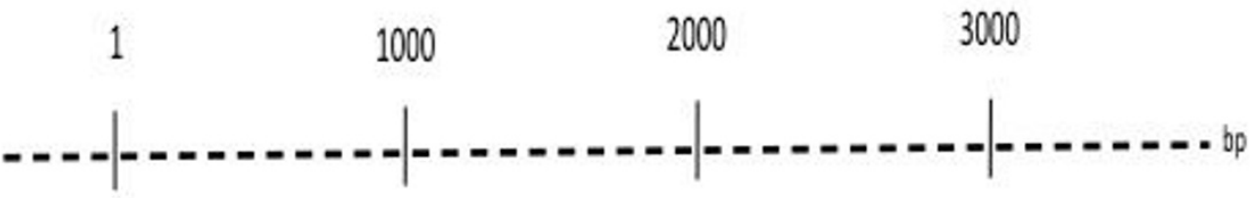

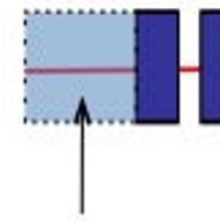

CCATTATTGS Potential CArG box

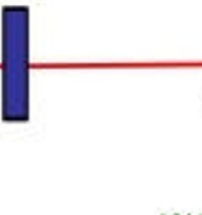

ACAAARAAGC Potential CArG boor

\section{CCATTGT}

Potential LFY binding site

Figure 4 Schematic of SpAP3 and SpPI gene structures. Dark blue boxes represent amino acid encoding regions. Light blue boxes represent 5 ' UTR and control regions. Thin red lines represent introns. SpAP3 has seven exons and six introns. The introns are 153 bp, 2522 bp, 96 bp, 295 bp, 103 bp, and $943 \mathrm{bp}$ in length respectively. Due to the lack of reliable 5' RACE data, the first exon start site is uncertain, however, the coding region of exon 1 extends $191 \mathrm{bp}$ starting from the first position of the start codon. The remaining exons 2, 3, 4, 5, and 6 are $67 \mathrm{bp}, 62 \mathrm{bp}, 100 \mathrm{bp}, 42 \mathrm{bp}$, and $45 \mathrm{bp}$ in length, respectively, while exon 7 starts 138 bp through the stop codon and continues another 238 bp past the stop codon, although only 182 bp of this 3' untranslated region was included in the present survey. SpPI has sevens exons and six introns. The introns are 117 bp, 1504 bp, 388 bp, 127 bp, $912 \mathrm{bp}$, and $253 \mathrm{bp}$ in length, respectively. Exon 1 extends to position 188 starting from the first position of the start codon. Exons 2 through 6 are 67 bp, 62 bp, 100 bp, 30 bp, and 45 bp long, respectively. Exon 7 starts 120 bp before the end of the stop codon and continues 169 past the stop codon. Positions of potential LEAFY binding elements and CArG boxes are indicated. 

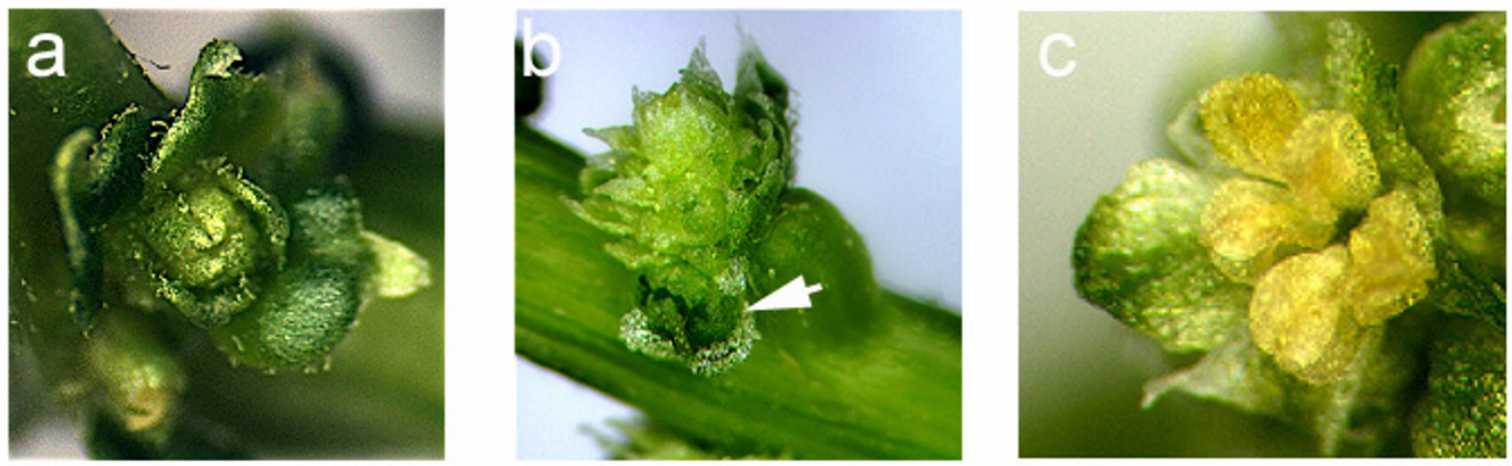

Figure 5 SpAG-silenced flowers. a. Flower with complete loss of stamens or carpels in a female silenced plant. b. New inflorescence meristem emerging from center of flower on a male plant. Adjacent flower has four sepals and four opposite sterile organs (arrow). c. Stamens of male flower that failed to mature and produce pollen.

\section{Discussion}

Analysis of sex determination in plants must begin with a clear understanding of where in the developmental process the gender commitment is established. This commitment stage will define what genes are already activated and hence not involved in sex determination, and which ones are yet to be activated, and hence are potential regulation points. Zea mays, Rumex acetosa, and Silene latifolia all begin floral development with both stamens and carpels. In all of these cases, B and C class floral organ identity genes are expressed early in male and female flowers and thus are not involved in triggering sexual differentiation [20,22,36,37]. In contrast, in both Thalictrum dioicum [25] and Spinacia oleracea [26], in which sexual differentiation occurs at the organ inception stage, B and C class floral organ identity are differentially expressed at floral initiation. Within such systems, it is logical to argue that sex determination can be regulated at the level of expression of the $\mathrm{BC}$ floral development genes or immediately upstream in the regulatory pathway. However, this can only be tested through functional analysis of these genes in their native context.

\section{SpAGAMOUS retains floral organ identity and meristem determinacy functions in spinach}

A single $\mathrm{C}$ class gene has been previously described in Spinacia oleracea and has been shown to be expressed early throughout the early floral meristem in both males and females [27]. After sepal initiation, $S p A G$ is expressed within the incipient stamen meristems in males and in the center of the floral meristem in females. In maturing male flowers, the expression becomes restricted to the pollen mother cells, whereas in the females the expression is found both in the center of the fourth whorl and at the distal tips of the growing gynoecial girdle. In mature females, $S p A G$ is expressed in the nucellus [27].

$S p A G$ appears to have three main functions in spinach flower development. First, $S p A G$ is required to establish reproductive organ identity. In males, the most extremely affected flowers displayed sterile green third whorl structures in place of stamens (Figure 5B). In females, loss of $S p A G$ activity resulted in the loss of carpels. Second, in males in which stamen-like structures did develop, no pollen was produced. These results presumably reflect silencing of $\operatorname{SpAG}$ at the developmental stage when the expression is restricted to the microsporangium (Figure 5C). Therefore, the spinach $\mathrm{C}$ class gene appears to be required for microsporogenesis. These observations conform to reports in Arabidopsis that AGAMOUS controls microsporogenesis through activation of SPOROCYTELESS (NOZZLE) [38]. We did not detect female flowers with phenotypically deformed ovaries and so we were not able to determine whether late silencing in females resulted in an analogous loss of megagametophyte development from loss of $S p A G$ nucellar expression. Third, the spinach C class gene controls floral determinacy. In extreme female phenotypes, floral organs were replaced by bract-like organs, organized in a continuous spiral phyllotaxy. These flowers had an obvious loss of determinacy, as evidenced by the continual formation of new whorls inside the previous whorl. Additionally, $\operatorname{SpAG}$ silenced males and females both initiated new inflorescence meristems within developing flowers. These results clearly indicate that the $\mathrm{C}$ class organ identity and meristem determinacy functions previ- 
ously described in Arabidopsis are conserved in spinach. The male floral phenotype also suggests that once the fourth whorl is suppressed in males, loss of $\operatorname{SpAG}$ is not sufficient to generate an indeterminate flower.

The phenotype, in which continuous sterile whorls develop, appears to be remarkably similar to the flower reported in the Arabidopsis ap2 pi ag triple mutant [39]. As B class genes are not expressed in spinach female flowers [26], the knockdown of $S p A G$ should be comparable to the double ag pi Arabidopsis mutant in which multiple whorls of sepals develop due to the expanding A class expression. The more leaf-like organs in the spinach $S p A G$ knockdown imply that genes homologous to SEPALLATA or AP1/FUL are not being expressed extensively throughout the flower or that they are not sufficient to define tepal identity. Recent work appears to support this hypothesis as the spinach $A P 1$ homologue appears to be expressed only at the initiation of the floral meristem and later in the stamens or carpels, but not in the sepals [40].

\section{Spinach B class genes define organ identity and are involve in sexual determination and sexual dimorphism}

We previously reported on the gender-specific expression patterns of both spinach B class genes. Both genes are expressed in males and, while $S p A P 3$ is initially expressed at low levels in females, $S p P I$ is not expressed in females at any stage [26]. In plants infected with pWSRi:SpAP3, female plants were unaffected. This suggests that the low level of wild type SpAP3 expression in female flowers is of no functional significance. The B class proteins in Arabidopsis and other species are reported to form heterodimers and to be functional only when both are present [41-43]. Additionally, continued expression of these genes beyond their original initiation by inflorescence identity genes is dependent on the PI/AP3 dimer acting to maintain PI and $A P 3$ expression [44,45]. Similarly, the lack of phenotypic effect in $p W S R i: S p A P 3$ treated plants is consistent with the lack of detectable expression of $S p A P 3$ and shows that this gene product is not required for proper female development.

Both SpPI- and SpAP3-suppressed male plants all form at least some mixed organ flowers, with homeotic transformations of stamens into carpels in the third whorl (Figures 1c, $1 d$, and 2b). Given these homeotic transformations, it seems that $\mathrm{B}$ class genes play a similar role in organ identity determination as has been shown in A. thaliana and other model species. In flowers of B-suppressed plants, aberrant organs were all in the third whorl, indicating that the fourth whorl had already been suppressed at the time when organ primordia were initiated.

Some flowers in $p W S R i: S p A P 3$ and $p W S R i: S p P I$ plants had a fourth whorl carpel, lacked third whorl stamens, but produced four tepals (Figure 1f). Other flowers developed as hermaphrodites with organs in the first, third, and fourth whorls (Figures 1e and 2a). Because wild type male flowers have four tepals, as contrasted with female flowers that have two, the fact that hermaphrodite flowers produced four tepals suggests that male identity had been established earlier in floral ontogeny. Lastly, wild type female flowers were also detected on treated male plants suggesting that earlier B class gene silencing can cause a complete switch in sexual development in the flowers.

As a sex-labile species, spinach is able to modify its sex based on environmental conditions [46]. To achieve sexual plasticity, sex determination is presumably regulated by a system capable of integrating inputs into the regulatory pathway, and able to affect downstream structural gene expression based on those environmental cues. As previously argued, the B class genes are attractive candidates as regulators of sex determination in spinach. It has been shown that B class genes in Arabidopsis are direct regulatory targets of gibberellic acid (GA) [47], a hormone capable of causing large male bias when applied to spinach $[48,49]$. Our results in which wild-type female flowers form on B class gene silenced plants indicate that expression of these $\mathrm{B}$ class gene functions as a key regulator of sex determination in spinach.

\section{A Model for Sex Determination and Sexual Dimorphism in Spinach}

Charlesworth and Charlesworth [50] proposed a model for the evolution of dioecious species. The steps involved include the initial evolution of a feminizing mutation that represses the formation of viable male gametes, resulting in a gynodioecious population of plants that are either female or hermaphroditic. The second stage involves the development of a masculinizing factor that represses the gynoecium in hermaphrodites, leading to the development of male flowers. The third stage includes the suppression of recombination of the masculinizing and feminizing factors by chromosomal linkage and inversion. The result is the establishment of sex determining superloci that allow for segregation of male and female determining factors within a dioecious population.

Prior to the present work, the specific genetic elements that control sex-determination in spinach have been unknown. Rosa [51] argued that sex was determined by genetic factors in spinach. In a series of papers, Janick and colleagues demonstrated that a male determining element (Y) existed on chromosome 6 [52-55] and a female determining element $(\mathrm{X})$ existed on chromosome 1 [56]. There is no evidence, however, of reduced recombination or chromosomal evolution leading to distinguishable $\mathrm{X}$ and $\mathrm{Y}$ chromosomes [57,58]. Alternatively, Chailakhyan $[48,59]$ demonstrated that female plants treated with exogenous gibberellic acid (GA) will produce male flowers, indicating that sex determination can be altered by exogenous applications of the plant hormone. Therefore, the regulation of the 
genetic factors must be coordinated by elements in the GA regulatory network.

Based on these earlier studies and our present work, we can propose a new model for sex determination in spinach (Figure 6). Pfent et al. [26] demonstrated that the B class genes are only expressed in male flowers and the present study illustrates that suppression of B class expression results in the development of female flowers. This switch of development from male to female flowers is not simply the result of homeosis, as both the number and the whorl location of the organs differ in addition to the organ identity itself. Thus, in spinach, the feminizing mutation must be in the suppression of B class expression. Therefore, an ancestral population in which a gene that regulates the expression of B class genes segregates, would have been gynodioecious, being composed of plants that produced either female (B class genes off) or hermaphroditic (B class genes on) flowers.

We propose that the masculinizing mutation regulated the termination of the flower in the third whorl, rather than in the fourth whorl. Our present study shows that $A G$ control of meristem termination is conserved in spinach. Yet, in both spinach and Arabidopsis, AGAMOUS is expressed in the third whorl. In Arabidopsis, this expression does not result in the termination of the flower in the third whorl. However, in spinach, when the B class genes are partially suppressed in male plants, the fourth whorl develops, implying the spinach B class genes are involved in early flower termination and suppression of the fourth whorl. Therefore, the prediction is that the masculinizing mutation, resulting in the suppression of the fourth whorl, occurred in the spinach B class genes or just downstream thereof.

Under this model, there is no requirement for active suppression of recombination. Once the B class genes become fixed in the population, as they appear to be, they will not segregate among individual offspring. The feminizing mutation is then epistatic to the masculinizing mutation. When the B class genes are expressed, male-only flowers develop. When the B class genes are not expressed, femaleonly flowers develop. Therefore, segregation is only necessary at a single locus. Hence, there is no need or expectation for the evolution of sex chromosomes in spinach.

\section{Conclusion}

We have reported here on the functional characterization of B class floral homeotic genes in a species that develops flowers that are unisexual from inception. While we have identified $S p P I$ and $S p A P 3$ as a key factors in both floral organ identity and sexual dimorphism in spinach, it is likely that regulation of sex determination originates upstream of the floral organ identity genes. If the regulation of sex determination originates upstream, then the B class genes clearly are key integrating points in the regulatory cascade. Furthermore, it appears that the B-class genes themselves have likely been the loci of the masculinizing mutations that terminate potentially hermaphroditic flowers before they can produce carpels. The evolutionary and developmental mechanisms will become clearer as known regulators of the B class genes are isolated and functionally characterized in spinach and in other species that produce imperfect flowers.

\section{Methods}

\section{Plant Growth Conditions}

Seeds from Spinacia oleracea L. cv. America (Twilley Seed Co., Inc., Trevose, PA) were planted in Miracle Gro ${ }^{\odot}$ potting soil and grown in growth chambers at $20^{\circ} \mathrm{C}$ under long day conditions ( $18 \mathrm{~h}$ light, $6 \mathrm{hrs}$ dark).

\section{Construction of pWSRi:SpAP3, pWSRi:SpPI, and pWSRi:SpAG}

The $p W S R i$ (plasmid Wayne State RNAi) vector was constructed from the Beet Curly Top Virus (BCTV) [29]. The BCTV genome contains two sets of structural genes, termed $\mathrm{L}$ and $\mathrm{R}$, which are transcribed from opposite directions toward the center. The multi-cloning site in pWSR $i$ containing XhoI and NotI restriction sites was constructed in the center of the genome inside the truncated R3 gene. A 305 base pair XhoI/NotI fragment from the 3 ' region of $S p P I$ was ligated into XhoI/NotI digested $p W S R i$ to create the vector $p W S R i: S p P I$. A 263 base pair XhoI/NotI fragment of SpAP3, similarly from the 3' region of the gene, was ligated into XhoI/NotI digested $p W S R i$ to create the vector $p$ WSRi:SpAP3. A $250 \mathrm{bp}$ fragment in the 3' end of $S p A G$ was subcloned into pGEM-T-Easy (Promega, Madison, WI, USA), adding XhoI and NotI restriction sites on the ends of the fragment. The XhoI/NotI fragment was then subcloned into Xhol/NotI digested $p W S R i$. Vector clones were verified by sequencing using cycle-sequencing with ABI BigDye ${ }^{\circledR}$ Terminator v3.1 chemistry. The sequencing reaction products were read on an Applied Biosytems ABI Prism 3700 (PE Applied Biosystems, Foster City, CA, USA).

\section{Biolistic infection of pWSRi:SpAP3, pWSRi:SpPI, and pWSRi:SpAG into spinach plants}

Spinach plants were selected at the four-leaf stage before they had transitioned into reproductive growth for biolistic infection of $p W S R i$ vectors. Plant were inoculated with $p W S R i$ vectors using the Helios ${ }^{\mathrm{TM}}$ Gene Gun (Bio-Rad Laboratories, Inc, Hercules, CA, USA). Plasmids were prepared by mixing approximately 10 micrograms of plasmid DNA in $\mathrm{sdH}_{2} \mathrm{O}$ with $20 \mathrm{mg}$ of tungsten powder. The slurry was mixed well, spread on a microscope slide, and the liquid was allowed to evaporate. Bullets were made by first coating plastic tubing (Bio-Rad) with a PVP solution then drying the tubing by a continuous nitrogen gas flush. Plasmid coated tungsten powder was placed in the tubing and 


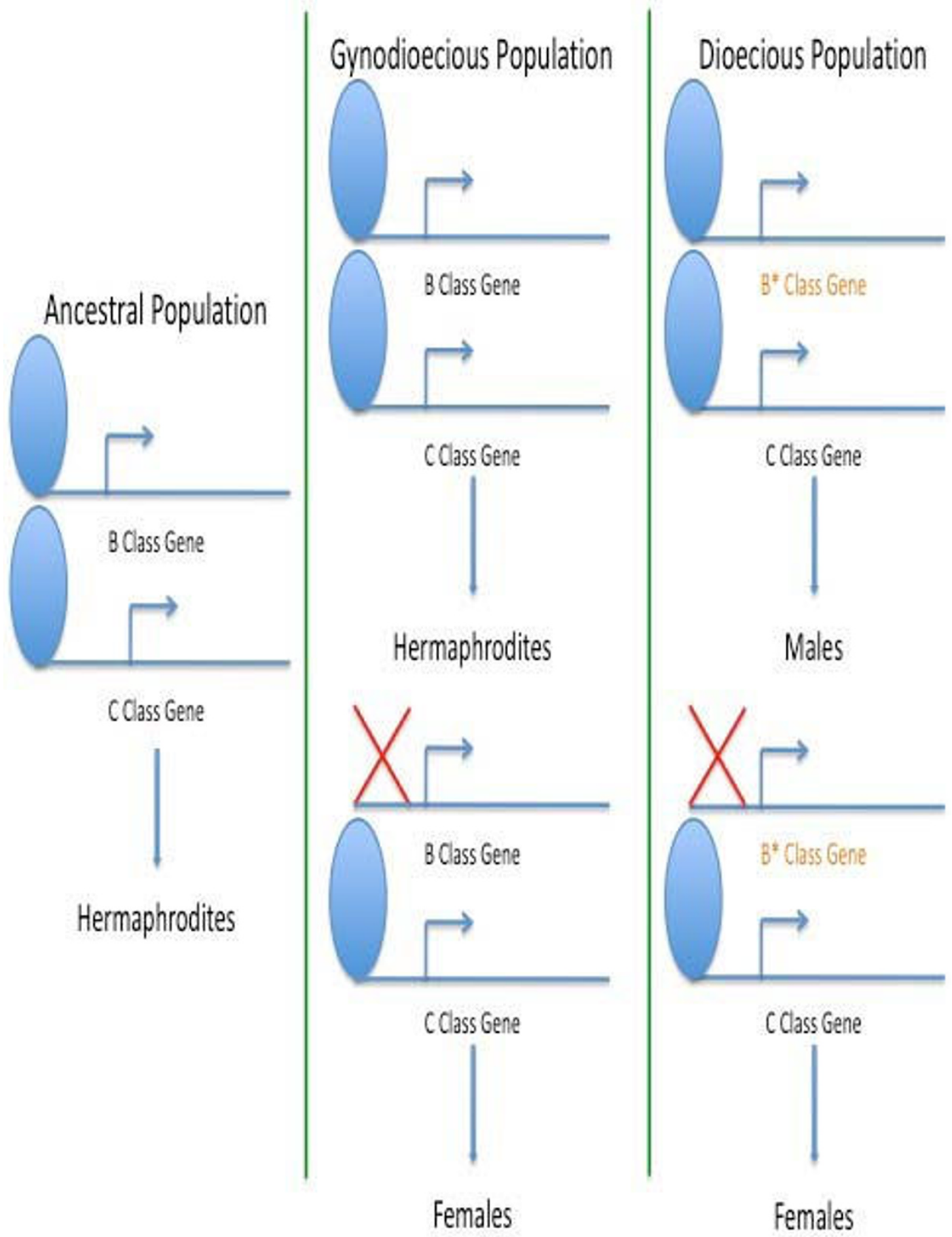

Figure 6 Model for the evolution of dioecy in spinach. In the ancestral hermaphroditic species, upstream elements, including but not limited to GA and LFY, activate both B (PI and AP3) and C (AG) class genes. Both classes of genes retain organ identity functions as described in the ABC model. Mutations in the $B$ class genes, notated by ${ }^{*}$, result in premature termination of the flower in the third whorl, and thus the loss of the carpel. The resultant flower is male. Inactivation or suppression of expression of the B class genes, modulated by the GA response pathway, results in the expression of AG only. The absence of B class gene products causes a reduction in the number of organs in the first whorl and the formation of a single, terminal carpel. The resultant flower is female. 
allowed to coat the walls. The tubing was then cut to the correct length for use in the Helios ${ }^{\mathrm{TM}}$ Gene Gun. Plants were bombarded at 90 PSI in the center of the developing plant from a distance of one inch. Plants were then transferred to a growth chamber at $23^{\circ} \mathrm{C}$ and grown under short day conditions ( 8 hours light, 14 hours dark) for three weeks. The plants were then switched to long day conditions and allowed to flower.

\section{Quantitative Real-time RT-PCR}

Total RNA was extracted from male inflorescences of $p W S R i: S p P I$ and $p W S R i$ (control) treated plants using Trizol following the manufacturer's protocol. Concentration of the total RNA was estimated by spectrophotometry. Total cDNA from approximately one microgram of RNA was made using random hexamers as primers and M-MLV Reverse Transcriptase using standard protocols. One ul $\mathrm{RNase} \mathrm{H}$ was then added to digest the RNA.

PCR reactions were prepared in batch using the $2 \times$ Master Sybr Green PCR mixes (Applied Biosystems) without primers for each cDNA sample so that comparisons between levels mRNA of the control gene (G6pdh) and the experimental $(S p P I)$ would not be affected by differential cDNA loading errors. Primers were designed to have similar annealing temperatures and to produce products of roughly the same size for each gene. For each cDNA sample, the reaction volumes were then divided into two tubes (4 reactions each), and the specific primer pairs were added. The reactions were then divided into four replicate reactions and placed in staggered wells in the PCR machine. The PCR temperature settings were $94^{\circ} \mathrm{C}$ for 10 minutes followed by 40 cycles of $94^{\circ} \mathrm{C} 15$ seconds, $54^{\circ} \mathrm{C} 15$ seconds, and $72^{\circ} \mathrm{C} 45$ seconds, and reactions were run and the data collected on a Stratagene Mx3000P. Mean threshold cycles for the $S p P I$ and $G 6 p d h$ reactions were calculated for each sample. The delta CT (Threshold cycle Chelatase -Threshold cycle $_{18 S}$ ) was calculated from the means and the delta $\mathrm{CT}$ variances were calculated by summing the individual $\mathrm{CT}$ variances as there should be no covariance of the sample errors.

\section{In Situ Hybridization}

Plants were harvested approximately six weeks after biolistic infection with $p W S R i$ clones and immersed in PROTOCOL 10\% Buffered Formalin (Fisher Chemicals, Fairlawn, NJ, USA) at $4^{\circ} \mathrm{C}$ for ten hours. Inflorescences were dehydrated in a graded ethanol series, cleared in HistoClear ${ }^{\odot}$ (National Diagnostics, Atlanta, GA, USA), and embedded in Paraplast Plus ${ }^{\odot}$ (Fisher Chemicals, Fairlawn, NJ, USA) paraffin before sectioning into 8 um sections. Anti-sense and sense strand RNA probes labeled with Digoxigenin-11UTP were prepared for $S p A P 3, S p P I$, and $S p A G$ as previously described [26,27]. Pre-hybridization clearing, rehydration, and hybridization were performed according to
Ambion's (Austin, TX, USA) mRNA-locator In situ Hyb kit. Sectioned inflorescences were hybridized with antisense or sense RNA probes at $50^{\circ} \mathrm{C}$ for 4 hours. One $2 \times$ SSC and two $1 \times$ SSC post-hybridization washes of 20 minutes were done at $50^{\circ} \mathrm{C}$ followed by equilibration in maleic acid buffer $(0.1 \mathrm{M}$ maleic acid, $0.15 \mathrm{M} \mathrm{NaCl}, 0.1 \%$ Tween$20, \mathrm{pH} 7.5$ ) for ten minutes. Sections were blocked with $0.1 \%$ BSA in maleic acid buffer for one hour before a onehour incubation with a 1:5000 dilution of anti-Digoxigenin antibody conjugated to an alkaline phosphatase (Roche, Indianapolis, IN, USA). Sections were washed four times in maleic acid buffer for twenty minutes before development. Color precipitate was achieved by incubation in a NBT/ BCIP solution (Roche, Indianapolis, IN, USA), then stopped by washing in sterile water. Sections were covered in Permount ${ }^{\circ}$ mounting media (Fisher, Fairlawn, NJ, USA) before the addition of a coverslip. Samples were viewed on a Zeiss compound light microscope with differential interference contrast (Normarski) optics. Photographs were taken on a SPOT RT v3.0 digital camera system and imported into Adobe Photoshop 7.0 for contrast adjustment. Floral stages were described as in Sather, et al., (2005).

Genomic sequence analysis of B class floral homeotic genes Genomic DNA from three male and three female individuals was isolated using Promega Wizard Genomic DNA purification kit. To isolate fragments of the SpPI gene, nine sets of overlapping primers were designed to search for allelic differences between males and females. For the $S p A P 3$ genomic male-female DNA comparison, 15 pairs of overlapping primers were designed and applied to the DNA of three male and three female individuals. Each set of primers was designed to amplify approximately 800 base pairs of genomic DNA with each consecutive primer pair amplifying approximately 400 base pairs of sequence amplified with previous primer set. The sequences of all the primers are listed in Additional file 1: Table S1. PCR reactions were cleaned using Wizard SV Gel and PCR CleanUp kit, direct sequencing was performed using PI specific primers, and sequences were analyzed using SEQUENCHER program.

\section{Additional material}

$$
\begin{aligned}
& \text { Additional file } 1 \text { Primer pairs used to amplify genomic sequences of } \\
& \text { the spinach genes SpPI and SpAP3. This file contains the sequences of } \\
& \text { the PCR primers used to amplify sequential, overlapping fragments of the } \\
& \text { genes SpPI and SpAP3. }
\end{aligned}
$$

\section{Authors' contributions}

DNS executed the gene silencing and in situ hybridization experiments, interpreted the data and contributed to the design of the project and to the writing of the manuscript. MJ executed the genetic sequencing and analysis. EMG conceived of the study, contributed to the gene silencing experiments, interpreted the data, and contributed to the writing of the manuscript. 


\section{Acknowledgements}

We would like to thank the reviewers for their suggestions to improve this paper. In particular, we would like to acknowledge Dr. David Baum for his patient, insightful, and extensive comments throughout the text. His corrections and suggestions invariably improved the clarity of the text or corrected errors. Any residual obtuse passages remain our responsibility.

\section{Author Details}

1Department of Biological Sciences, Wayne State University, Detroit, MI 48202, USA and ${ }^{2}$ Current address: Seattle Biomedical Research Institute, 307 Westlake Avenue N, Seattle, WA 98109, USA

Received: 2 October 2009 Accepted: 12 March 2010

Published: 12 March 2010

\section{References}

1. He C, Munster T, Saedler H: On the origin of floral morphological novelties. FEBS Lett 2004, 567(1):147-151.

2. Kanno A, Nakada M, Akita Y, Hirai M: Class B gene expression and the modified ABC model in nongrass monocots. ScientificWorldJournal 2007, 7:268-279.

3. Kanno A, Saeki H, Kameya T, Saedler H, Theissen G: Heterotopic expression of class B floral homeotic genes supports a modified ABC model for tulip (Tulipa gesneriana). Plant Molecular Biology 2003, 52(4):831-841.

4. Hirai M, Kamimura T, Kanno A: The expression patterns of three class B genes in two distinctive whorls of petaloid tepals in Alstroemeria ligtu. Plant Cell Physiol 2007, 48(2):310-321

5. Park JH, Ishikawa Y, Ochiai T, Kanno A, Kameya T: Two GLOBOSA-like genes are expressed in second and third whorls of homochlamydeous flowers in Asparagus officinalis L. Plant Cell Physiol 2004, 45(3):325-332.

6. Irish VF, Kramer EM: Genetic and molecular analysis of angiosperm flower development. Advances in Botanical Research 1998, 28:197-230.

7. He C, Saedler H: Hormonal control of the inflated calyx syndrome, a morphological novelty, in Physalis. Plant J 2007, 49(5):935-946.

8. He C, Saedler H: Heterotopic expression of MPF2 is the key to the evolution of the Chinese lantern of Physalis, a morphological novelty in Solanaceae. Proc Natl Acad Sci USA 2005, 102(16):5779-5784.

9. Kramer EM, Holappa L, Gould B, Jaramillo MA, Setnikov D, Santiago PM: Elaboration of B Gene Function to Include the Identity of Novel Floral Organs in the Lower Eudicot Aquilegia. Plant Cell 2007, 19(3):750-766.

10. Ambrose BA, Lerner DR, Ciceri P, Padilla CM, Yanofsky M, Schmidt RJ: Molecular and genetic analysis of the Silky1 gene reveal conservation in floral organ specification between eudicots and monocots. Mol Cell 2000, 5:569-579.

11. Kyozuka J, Kobayashi T, Morita M, Shimamoto K: Spatially and temporally regulated expression of rice MADS box genes with similarity to Arabidopsis class A, B and C genes. Plant Cell Physiol 2000, 41:710-718.

12. Munster T, Ursula Wingen L, Faigl W, Werth S, Saedler $H$, Thei[ss]en G: Characterization of three GLOBOSA-like MADS-box genes from maize: evidence for ancient paralogy in one class of floral homeotic Bfunction genes of grasses. Gene 2001, 262(1-2):1-13.

13. Whipple CJ, Ciceri P, Padilla CM, Ambrose BA, Bandong SL, Schmidt RJ: Conservation of $\mathrm{B}$-class floral homeotic gene function between maize and Arabidopsis. Development 2004, 131(24):6083-6091.

14. Xiao H, Wang Y, Liu D, Wang W, Li X, Zhao X, Xu J, Zhai W, Zhu L: Functional analysis of the rice AP3 homologue OsMADS16 by RNA interference. Plant Molecular Biology 2003, 52:957-966.

15. Davies B, Motte P, Keck E, Saedler H, Sommer H, Schwarz-Sommer Z PLENA and FARINELLI: redundancy and regulatory interactions between two Antirrhinum MADS-box factors controlling flower development. Embo J 1999, 18(14):4023-4034.

16. Yamaguchi T, Lee DY, Miyao A, Hirochika H, An G, Hirano H-Y: Functional Diversification of the Two C-Class MADS Box Genes OSMADS3 and OSMADS58 in Oryza sativa. Plant Cell 2006, 18(1):15-28.

17. Heslop-Harrison J: Sex expression in flowering plants. In Brookhaven Symposia in Biology Volume 16. Upton, NY.: Brookhaven National Laboratory; 1964:109-125.

18. Golenberg EM, Freeman DC: Environmental sex expression, sexual lability, biased sex ratios and other X-rated stories from the far-red side of the garden. In Floriculture, Ornamental and Plant Biotechnology:
Advances and Topical Issues Edited by: Silva JATd. Japan: Global Science Books; 2006:280-291.

19. Delong A, Calderon-Urrea A, Dellaporta S: Sex-determination gene Tasselseed2 of maize encodes a short-chain alcohol dehydrogenase required for stage-specific floral organ abortion. Cell 1993, 74:757-768.

20. Ainsworth C, Crossley S, Buchanan Wollaston V, Thangavelu M, Parker J: Male and female flowers of the dioecious plant sorrel show different patterns of MADS box gene expression. Plant Cell 1995, 7(10):1583-1598.

21. Kater M, Franken J, Carney K, Colombo L, Angenent G: Sex determination in the monoecious species cucumber is confined to specific floral whorls. Plant Cell 2001, 13:481-493.

22. Hardenack S, Ye D, Saedler H, Grant S: Comparison of MADS box gene expression in developing male and female flowers of the dioecious plant White Campion. Plant Cell 1994, 6:1775-1787.

23. Hobza R, Hrusakova P, Safar J, Bartos J, Janousek B, Zluvova J, Michu E, Dolezel J, Vyskot B: MK17, a specific marker closely linked to the gynoecium suppression region on the $\mathrm{Y}$ chromosome in Silene latifolia. Theor Appl Genet 2006, 113(2):280-287.

24. Zluvova J, Nicolas M, Berger A, Negrutiu I, Moneger F: Premature arrest of the male flower meristem precedes sexual dimorphism in the dioecious plant Silene latifolia. Proc Natl Acad Sci USA 2006, 103(49):18854-18859.

25. Di Stilio VS, Kramer EM, Baum DA: Floral MADS box genes and homeotic gender dimorphism in Thalictrum dioicum (Ranunculaceae) - a new model for the study of dioecy. Plant $J$ 2005, 41(5):755-766.

26. Pfent C, Pobursky KJ, Sather DN, Golenberg EM: Characterization of SpAPETALA3 and SpPISTILLATA, B Class Floral Identity Genes in Spinacia oleracea, and Their Relationship to Sexual Dimorphism. Development Genes and Evolution 2005, 215:132-142.

27. Sather DN, York A, Pobursky KJ, Golenberg EM: Sequence evolution and sex-specific expression patterns of the C class floral identity gene, SpAGAMOUS, in dioecious Spinacia oleracea L. Planta 2005, 222:284-292.

28. Sherry RA, Eckard KJ, Lord EM: Flower development in dioecious Spinacia oleracea (Chenopodiaceae). American Journal of Botany 1993, 80:283-291

29. Golenberg EM, Sather DN, Hancock LC, Buckley KJ, Villafranco NM, Bisaro DM: Development of a gene silencing DNA vector derived from a broad host range geminivirus. Plant Methods 2009, 5(1):9.

30. Goto K, Meyerowitz EM: Function and regulation of the Arabidopsis floral homeotic gene PISTILLATA. Genes and Development 1994, 8(13):1548-1560.

31. Devon RS, Porteous DJ, Brookes AJ: Splinkerettes--improved vectorettes for greater efficiency in PCR walking. Nucl Acids Res 1995, 23(9):1644-1645.

32. Hill TA, Day CD, Zondlo SC, Thackeray AG, Irish VF: Discrete spatial and temporal cis-acting elements regulate transcription of the Arabidopsis floral homeotic gene APETALA3. Development 1998, 125:1711-1721.

33. Folter $\mathrm{Sd}$, Angenent GC: trans meets cis in MADS science. Trends in Plant Science 2006, 11(5):224-231.

34. Lamb RS, Hill TA, Tan QK-G, Irish VF: Regulation of APETALA3 floral homeotic gene expression by meristem identity genes. Development 2002, 129(9):2079-2086.

35. Busch MA, Bomblies $K$, Weigel D: Activation of a floral homeotic gene in Arabidopsis. Science 1999, 285(5427):585-587.

36. Schmidt RJ, Veit B, Mandel MA, Mena M, Hake S, Yanofsky MF: Identification and molecular characterization of ZAG1, the maize homolog of the Arabidopsis floral homeotic gene AGAMOUS. Plant Cell 1993, 5(7):729-737.

37. Ainsworth C, Rahman A, Parker J, Edwards G: Intersex inflorescences of Rumex acetosa demonstrate that sex determination is unique to each flower. New Phytol 2005, 165(3):711-720.

38. Ito T, Wellmer F, Yu H, Das P, Ito N, Alves-Ferreira M, Riechmann JL, Meyerowitz EM: The homeotic protein AGAMOUS controls microsporogenesis by regulation of SPOROCYTELESS. Nature 2004, 430(6997):356-360

39. Bowman JL, Smyth DR, Meyerowitz EM: Genetic interactions among floral homeotic genes of Arabidopsis. Development 1991, 112:1-20.

40. Sather D, Golenberg E: Duplication of AP1 within the Spinacia oleracea L. AP1/FUL clade is followed by rapid amino acid and regulatory evolution. Planta 2009, 229(3):507-521. 
41. Riechmann JL, Krizek BA, Meyerowitz EM: Dimerization specificity of Arabidopsis MADS domain homeotic proteins APETALA1, APETALA3, PISTILLATA, and AGAMOUS. Proc Natl Acad Sci USA 1996, 93:4793-4798.

42. Riechmann JL, Meyerowitz EM: Determination of floral organ identity by Arabidopsis MADS domain homeotic proteins AP1, AP3, PI, and AG is independent of their DNA-binding specificity. Mol Biol Cell 1997, 8:1243-1259.

43. Riechmann JL, Wang M, Meyerowitz EM: DNA-binding properties of Arabidopsis MADS domain homeotic proteins APETALA1, APETALA3, PISTILLATA and AGAMOUS. Nucleic Acids Res 1996, 24(16):3134-3141.

44. Honma T, Goto K: The Arabidopsis floral homeotic gene PISTILLATA is regulated by discrete cis-elements responsive to induction and maintenance signals. Development 2000, 127:2021-2030.

45. Schwarz-Sommer Z, Hue I, Huijser P, Flor P, Hansen R, Tetens F, Lonnig W, Saedler $\mathrm{H}$, Sommer H: Characterization of the Antirrhinum floral homeotic MADS-box gene deficiens: evidence for DNA binding and autoregulation of its persistent expression throughout flower development. EMBO J 1992, 11(1):251-263.

46. Freeman DC, Vitale JJ: The influence of environment on the sex ratio and fitness of spinach. Botanical Gazette 1985, 146:137-142.

47. Yu H, Ito T, Zhao Y, Peng J, Kumar P, Meyerowitz EM: Floral homeotic genes are targets of gibberellin signaling in flower development. Proc Natl Acad Sci USA 2004, 101(20):7827-7832.

48. Chailakhyan MK: Genetic and hormonal regulation of growth, flowering, and sex expression in plants. American Journal of Botany 1979, 66:717-736.

49. Pobursky KJ: Early flower development and the influence of gibberellic acid on sex expression in Spinacia oleracea. In Master of Science Detroit, Ml: Wayne State University; 2000.

50. Charlesworth B, Charlesworth D: A model for the evolution of the dioecy and gynodioecy. Am Nat 1978, 112:975-997.

51. Rosa JT: Sex expression in spinach. Hilgardia 1925, 1:259-274.

52. Janick J, Stevenson EC: A genetic study of the heterogametic nature of the staminate plant in spinach. Proc Am Soc Hort Sci 1954, 63:444-446.

53. Janick J, Mahoney DL, Pfahler PL: The trisomics of Spinacia oleracea L. Journal of Heredity 1959, 50:46-50.

54. Mahoney DL, Janick J, Stevenson EC: Sex determination in diploidtriploid crosses of Spinacia oleracea. American Journal of Botany 1959, 46:372-375

55. Ellis JR, Janick J: The chromosomes of Spinacia oleracea. American Journal of Botany 1960, 47:210-214.

56. lizuka M, Janick J: Sex chromosome variation in Spinacia oleracea L. J Heredity 1971, 62:349-352.

57. Ramanna MS: Are there heteromorphic sex chromosomes in spinach (Spinacia oleracea L.)? Euphytica 1976, 25:277-284.

58. Khattak J, Torp A, Andersen S: A genetic linkage map of Spinacia oleracea and localization of a sex determination locus. Euphytica 2006, 148(3):311-318

59. Chailakhyan MK, Khrianin VN: Sexuality in plants and its hormonal regulation. New York: Springer-Verlag; 1987.

doi: $10.1186 / 1471-2229-10-46$

Cite this article as: Sather et al., Functional analysis of B and C class floral organ genes in spinach demonstrates their role in sexual dimorphism $B M C$ Plant Biology 2010, 10:46

Submit your next manuscript to BioMed Central and take full advantage of:

- Convenient online submission

- Thorough peer review

- No space constraints or color figure charges

- Immediate publication on acceptance

- Inclusion in PubMed, CAS, Scopus and Google Scholar

- Research which is freely available for redistribution

Submit your manuscript at www.biomedcentral.com/submit
C Biomed Central 